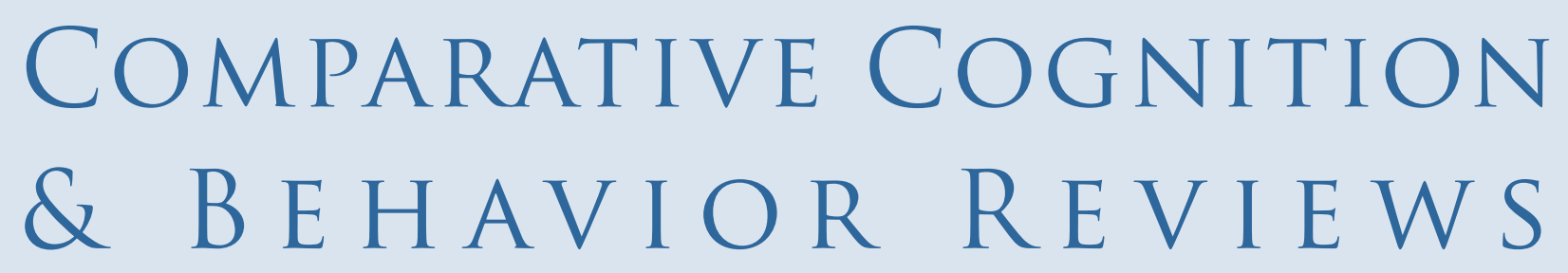

HOW-TO ARTICLE

\title{
Teaching Animal Learning and Cognition: Adapting to the Online Environment
}

\author{
Valerie A. Kuhlmeier \\ Queen's University
}

\author{
Tara A. Karasewich \\ Queen's University
}

\author{
Mary C. Olmstead \\ Queen's University
}

The number of online courses offered by institutions of higher education has been increasing sizably in the 21st century. As we write this article in 2020, though, the prevalence of online courses is taking an unexpected upturn as the global COVID-19 pandemic has led to a sudden transition of many in-person courses to remote, online delivery. The specific goal of this article is to share, in a timely manner, our experiences and insights from teaching an online course on animal learning and cognition for the last 7 years. A broader goal is to provide a resource that not only benefits instructors in the present circumstances but also supports course development, review, and redesign - for both on-campus and online curricula - into the future. To these ends, we discuss course organization, learning outcomes, activities, assessments, and considerations such as accessibility and academic integrity. We end with a "call for community" of instructors who share teaching resources, and we hope that this article, and its associated supplemental materials, may serve to support this endeavor.

\section{Keywords: online teaching, higher education, learning outcomes, animal learning}

\section{Introduction}

Coronavirus disease 2019 (COVID-19) is "the defining global health crisis of our time." (DirectorGeneral, World Health Organization, March 2020) With more than 8.9 million confirmed cases and a half-million deaths worldwide as of this writing (World Health Organization, 2020), the pandemic has dramatically altered social, political, and commercial activities in most countries. This includes a sudden transition to remote delivery of courses at educational institutions around the world. Despite the easing of restrictions surrounding physical distancing in some regions, many colleges and universities have already announced that they will continue to deliver the majority of their courses remotely in the upcoming academic year.

Even pre-pandemic, though, online courses were growing rapidly in North American higher education. Allen and Seaman (2016), for example, reported that the growth rate from 2013 to 2014 for the number of college and university students taking at least one online course in the United States was 3.9\%, up slightly from 3.7\% the previous year. Further, many students who take these courses are also taking courses in-person on campus: 
Allen and Seaman's survey found that in 2014, the number of students taking all of their courses online was almost equal to the number of students taking at least one, but not all, of their courses online (2.85 million and 2.97 million, respectively). (We encourage some caution when considering these numbers, however, as the survey included enrollment in Massive Open Online Courses, typically offered outside of an institution's primary curriculum. Massive Open Online Courses are otherwise not discussed in this article.) Other reports suggest that $30 \%$ of students in degree-granting U.S. colleges and universities enrolled in at least one online course (Allen \& Seaman, 2017), and $44 \%$ of faculty respondents reported teaching at least one fully online course (Jaschik \& Lederman, 2018).

We thus recognize that many of our colleagues may be scrambling to repurpose their courses because of the present pandemic and that some may have already had longer term plans to develop an online course within their departmental course offerings. The goal of this article is to share our experiences and insights from teaching an online course on animal learning and cognition for the past 7 years. To provide some context, our 12-week course, Introduction to Comparative Cognition, is offered through the Department of Psychology at a research-intensive university in a small Canadian city (Kingston, Ontario). The typical enrollment for the online course is 150-200 students per year, with an introductory psychology course being the only prerequisite. The majority of students are 2nd- and 3rd-year psychology majors, although we regularly have students from cognate disciplines such as biology, life sciences, and education, among others. We offer an on-campus (i.e., face-to-face) version of the same course in alternate terms, as well as two lab courses that are a continuation

Author Note: Valerie Kuhlmeier, Department of Psychology, Queen's University, Kingston, Ontario, Canada K7L 3N6.

Correspondence concerning this article should be addressed to Valerie Kuhlmeierat vk4@queensu.ca.

Acknowledgments: This work was supported by Discovery Grants from the Natural Sciences and Engineering Research Council of Canada to Mary C. Olmstead and Valerie A. Kuhlmeier and by a Doctoral Fellowship from the Social Science and Humanities Research Council of Canada to Tara A. Karasewich. The development of the online course described in this article was supported by the Queen's Faculty of Arts and Science Course Redesign Project, the Ontario Online Initiative, and Queen's University Arts and Science Online. Queen's University is situated on traditional Anishinaabe and Haudenosaunee Territory. of this foundational course (Comparative Cognition: Laboratory in Animal Learning and Comparative Cognition: Laboratory in Cognitive Origins). Neither of our lab courses is currently offered remotely, although we describe below how activities and assignments from these courses could be modified for online delivery.

Before proceeding, however, we wish to be clear that we do not advocate a complete replacement of in-person courses. Our perspective when creating our course was that online courses provide an additional option for students, particularly for those who would otherwise have difficulty attending on-campus meetings because of location, accessibility, and/or family or work responsibilities. In the current pandemic, however, the necessity of delivering online courses has superseded the value of alternate modes of delivery. A more ultimate goal of the present article is to provide a resource that benefits instructors in the present circumstances, yet also supports course development, review, and redesign - for both on-campus and online curricula - into the future. To this end, we have also included supplementary material (see Supplementary Information section below): (a) an annotated list of online resources (e.g., videos, podcasts, popular press) specific to courses on animal learning and cognition, (b) an annotated list of resources relevant to online teaching in any discipline (e.g., guides for developing accessible content, for recording of lectures, and for engaging students, etc.), and (c) instructions for how to contribute to these lists.

\section{Course Organization}

In all likelihood, most instructors already incorporate online components into their in-person teaching via web-based learning management systems (LMS) that contain course materials and assessments, provide forums for discussion, and track student progress. Major textbook publishers have begun to integrate material into some of the major LMS platforms (the "big four"): Blackboard Learn, D2L Brightspace, Moodle, and Instructure Canvas (Fenton, 2018). By at least 6 years ago, almost all higher education institutions in the United States had an LMS, and an estimated $83 \%$ of students were accessing the sites (2014 report by the Educause Center for Analysis and Research; Rhode et al., 2017).

Those studying pedagogy in higher education have developed categories of modern instructional models, and each model entails the use of online material to a varying extent and varying purpose. Courses that

COMPARATIVE COGNITION \& BEHAVIOR REVIEWS 
meet in-person for lectures by a primary instructor are often referred to as using a "traditional, lecturebased model," but students may have online access to readings, assignment submission, and quizzes. With the advancement of LMS, the line has blurred between the traditional model and what is referred to as the "blended" model in which face-to-face meetings are combined with online activities. A type of blended learning model, though, is the "flipped" model (or "flipped classroom"), in which material that would have traditionally be delivered in the lecture is delivered online, and classroom time is used for activities that would have traditionally been considered homework. Fully online courses can fall into one of these models, with the obvious difference that in-person meetings do not occur; these meetings might instead be replaced by asynchronous lectures that are prerecorded and accessible for viewing at any time, or by synchronous meetings in which students and instructors convene on platforms such as Zoom or Microsoft Teams at a scheduled time.

Between 2012 and 2015, we witnessed strong arguments played out in the popular press, often pitting instructors who preferred the traditional model (or, at least, a blended model that contained in-person lectures) against those advocating for the flipped model. Articles with titles such as "Twilight of the Lecture" (Lambert, 2012, in Harvard Magazine) and "Lectures Aren't Just Boring, They're Ineffective, too, Study Finds" (Bajak, 2014, in Science Insider, based on Freeman et al., 2014) were met with responses such as "In Defense of the Lecture" (Small, 2014, in The Chronicle of Higher Education) and "Lecture Me. Really." (Worthen, 2015, in the New York Times). In both our on-campus and fully online versions of Introduction to Comparative Cognition, we have chosen to incorporate lectures, though in the former they are complemented with online material and smaller section meetings in which activities are completed, and in the latter, the lectures are prerecorded and comparatively short (approximately $15 \mathrm{~min}$ ).

We have found that fully online courses require a clearly presented schedule to help students navigate material and meet deadlines. As such, there can be much more "front-end" work to prepare for the course compared with in-person courses, as the online course is completely developed prior to the start of the term. The instructional work that occurs during the term is typically focused on communication with students, moderating discussion forums, grading, and occasional tech support. Our course is organized into 12 units, one for each week of the term. All weeks begin with a written introduction that provides an overview of the topics, activities, and assignments in that unit. We use these introductions to spark interest in the topics by providing everyday anecdotes (e.g., one instructor's dog, Bradley, navigating his human grandmother's suburban neighborhood). The students then read a textbook chapter outside of the course LMS. They continue by watching a short prerecorded lecture that highlights a few key concepts and expands on specific issues or controversies that students may find difficult to understand (e.g., how sensory exploitation relates to sensory bias). A weekly low-stakes, open-book quiz and an activity follow (described more fully below). This

Figure 1. An example Week (or Unit) in our online Introduction to Comparative Cognition course. Students are encouraged to begin by reading a short

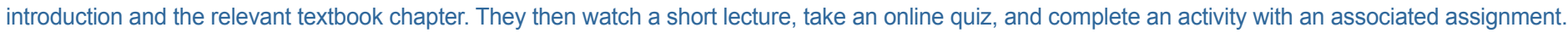

\section{Week 3 Workflow}
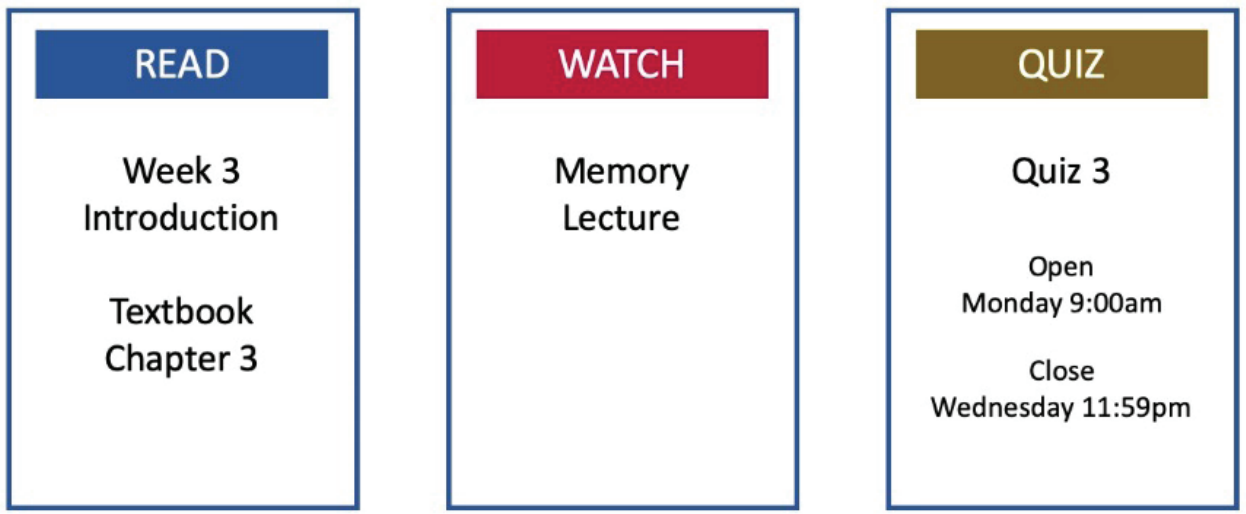

ACTIVITY

Measuring Memory

1. Read Instructions

2. Complete $\mathrm{N}$-back task

3. Submit Commentary 
workflow is made explicit to students though a graphical depiction of the steps (Figure 1).

Before continuing, we wish to note that in the current pandemic, instructors are developing courses within compressed time frames, and for many, modified workfrom-home schedules. Options such as synchronous lectures and activities may be desirable to some instructors and students, yet they may disadvantage those with caregiving responsibilities or slow internet connections and those who live in different time zones. Working from our current assumption that the in-person version of our course may need to be taught remotely in this upcoming academic year, we have decided to use asynchronous lectures similar to our online course, in part because of the constraints just listed. However, research has suggested that some students may not use prerecorded lectures in a manner that promotes learning; these students may be prone to a "surface learning" strategy, simply memorizing material, which is exacerbated by the availability of the lecture recordings (e.g., Le et al., 2010; Leadbeater et al., 2013). We attempt to discourage the use of such a strategy with clear learning outcome statements and through the asynchronous activities and assignments, both of which are detailed in the next sections.

\section{Learning Outcomes}

Seven years ago - within what may now, in the whirlwind of 2020, be seen as the luxury of time-we developed our on-campus and online courses in comparative cognition simultaneously. We specifically designed both courses to have the same learning outcomes, ensuring consistency across the two modes of delivery in what students were expected to learn and how they would demonstrate this learning (e.g., Fink, 2013). In line with best practices in higher education pedagogy (e.g., Hounsell \& Anderson, 2008; Kolomitro \& Gee, 2015), our learning outcomes encompass foundational knowledge, applications of this knowledge, and integration with other bodies of knowledge. In our experience, it is particularly important for online courses to have clearly articulated statements describing the knowledge, skills, and habits of mind that students are expected to display by course completion. Indeed, students identify a lack of clear goals and objectives for each course component as one of the primary challenges in online learning (Song et al., 2004).

We provide learning outcomes for the entire course and for each unit in the course, giving students a framework to organize the material and ensuring that they understand how it relates to other courses in their discipline. These are listed prominently on the course website and are reiterated in course announcements at the beginning of each unit. For example, a learning outcome from a unit on navigation may read, "By the end of this unit, students will be able to describe the methodology and results of laboratory tests of spatial learning in different species." An activity and assessment aligned with this learning outcome could require students to articulate the methods and functional explanations for the results of a study, then use this information to discuss the evolution of spatial cognition in an online forum.

On a more general level, the course is designed to introduce students to the field of comparative cognition, emphasizing its interdisciplinarity nature and explaining how research is conducted in this field. We discuss both proximate and ultimate explanations of different cognitive processes. Accordingly, the learning outcomes for the entire course include such items as "With successful completion of this course, students will be able to recognize and recall experimental findings that support or do not support existing theories in comparative cognition" and "... students will be able to apply theories to predict outcomes of experimental manipulations." We also embed the development of different aptitudes into our learning outcomes, mapping these onto degree-level expectations from our institution. These include critical thinking, communication, and social responsibility, among others. We recently argued that courses on comparative cognition are particularly well suited to developing these skills in that they promote divergent thinking by encouraging students to search for multiple interpretations of a given phenomenon (Lamontagne, Kuhlmeier, \& Olmstead, in press). As an example, the existence of theory of mind in nonhuman primates is particularly controversial; to understand the debate, students must think critically to integrate information across a variety of sources, question assumptions, and form an opinion about the topic. Communication is particularly important in the current climate of "fake news": We address this issue by providing links to primary sources when we post popular press articles or social media tweets related to comparative cognition. In terms of social responsibility and professionalism, research in comparative cognition has the potential to inform conservation efforts, one of the most pressing issue facing humanity.

COMPARATIVE COGNITION \& BEHAVIOR REVIEWS 


\section{Activities and Assignments}

A key element of each week of our online course is an activity designed to encourage student engagement. As an example, Week 1 begins with an activity that, at face value, seems trivial: Students complete a poll asking, "What is the smartest animal?" As with all of our activities, we assure students that they are not assessed on the activity itself (in this case, their response to the poll), but they must complete the activity before they can complete the associated assignment, which is graded. The smartest animal poll includes more than two dozen photos of different species, ranging from desert ants to elephants. As soon as students click on a response, they are shown anonymized poll results from the last few years of the course. Although some species always receive more votes than others (e.g., bottlenose dolphins typically score higher than honeybees), there are always some surprising blips. Recently, octopuses have made an impressive showing! Of course, the specific response that students provide is irrelevant. Rather, the assignment requires students to reflect on their choice by writing a short commentary on what criteria they used to rank intelligence. They also comment on why other students may have chosen a different species. Students often mention that this initial activity got them "hooked" on the course, challenging their assumptions about intelligence and questioning how it can be measured in subjects with such different capabilities and experiences.

Activities in later units follow a similar structure. For example, students complete an online working memory task (the N-back task), then complete an assignment in which they write a reflection on their own performance, including commenting on strategies they adopted as the task became more difficult. In our experience, students readily grasp the concept of working memory under these conditions and are able to discuss why this process has evolved in so many different species. Similarly, the unit on categorization and concept formation includes an online task that is modeled on an analogical reasoning paradigm in chimpanzees (Flemming \& Kennedy, 2011). We attempt to simulate the experience of nonhuman subjects by providing students with minimal instructions on how to perform the task. In their written assignment, students comment on cognitive processes that facilitate performance of this task and how these may be adaptive for species that evolved under different environmental constraints. Our unit on causality and tool use requires students to watch the BBC documentary The Problem Solvers: Inside the Animal Mind (Russell, 2014) via a library database at our institution. Students then answer a series of questions on social learning and culture, including commenting on a statement in the video (by Dr. Nicola Clayton) that "complexity isn't necessarily an accurate reflection of cleverness." The written assignments connected with these weekly activities become increasingly challenging as the course progresses, advancing student understanding of evolutionary principles in cognition.

Group activities are an ideal way to build community in online courses and may be particularly valued in this time of physical distancing. Within the 1st week of class, we ask students to introduce themselves in a virtual student café (a discussion board within our learning management system), prompting them with questions such as "What is your major?" and "Why did you decide to take this course?" and encouraging them to respond to their peers' posts. (Instructor resources pertaining to "netiquette" are available in the Supplementary Information section below.) We set a group assignment early in the term, encouraging students to work together virtually; prior to the COVID-19 pandemic, this often translated into face-to-face study groups. This initial assignment involves writing test questions (multiple-choice, short answer, and long answer) for a "mock" midterm exam using the Ideas, Connections, and Extensions (ICE) model (e.g., Fostaty Young \& Wilson, 2000; Figure 2). We post examples of the best questions from each category and then encourage students to provide answers to these questions on a course discussion board, which is monitored by the instructor and teaching assistants. In a second group assignment, we ask students to respond to another student's commentary, suggesting that they focus on similarities and differences in each of their responses. Thus, in addition to promoting student interaction, this interchange encourages them, once again, to reflect on their own biases and assumptions.

Our lab courses, which are currently designed for in-person meetings, include activities and assignments that could be adapted to online delivery. These include exercises in which students observe and quantify video recordings of animal behavior as a means to understand a particular cognitive process. Online resources are readily available showing a variety of species-typical behaviors, such as courting, aggression, play, and foraging. (An annotated list of these resources is available in the Supplemental Information section below.). We also rely on our own collection of video clips from animal lab experiments of different cognitive tasks. Depending on the academic level of the course, we provide students 


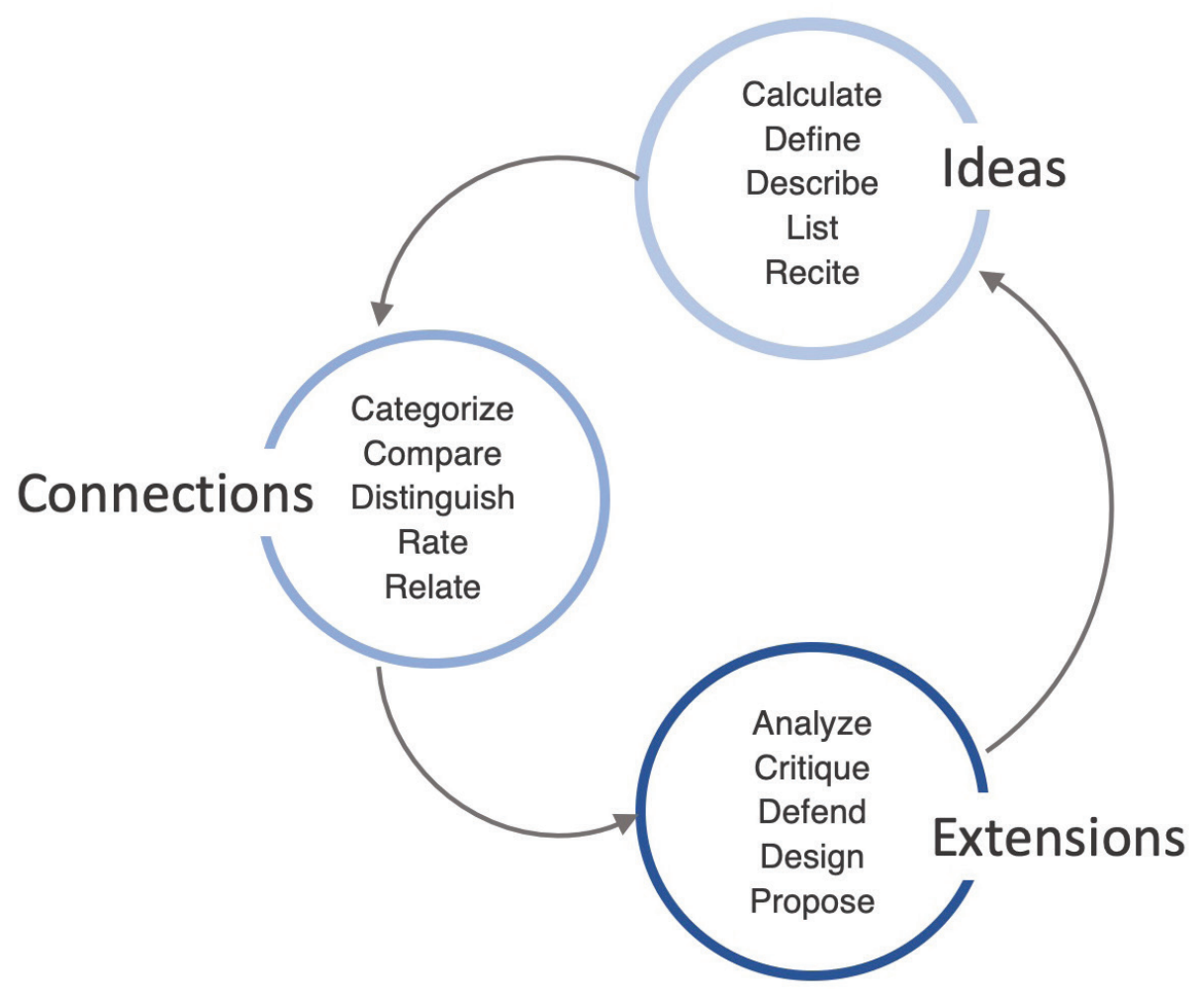

Figure 2. The ICE model of pedagogy by Fostaty Young and Wilson (2000) with example "verbs" for each node. In their model, Ideas (discrete pieces of information or discrete skills) are the initial building blocks, and Connections develop between them. Extensions are then made as the learning is used in novel ways and applied to novel situations, which then become the basis for new ideas. In an assignment in our course, students are encouraged to create mock exam questions that assess understanding in each of these three ways.

with behavioral ratings sheets or ask them to come up with their own evaluation system. Through this process, they begin to understand the relationship between operational definitions of a behavior and specific cognitive processes. As an example, students may record latencies to find a hidden platform across trials in the Morris water maze, then discuss how this relates to spatial cognition in the natural environment. In another lab, students observe and record behavior in the "natural" environment, which includes anything outside of the lab (e.g., insects invading their apartment, racoons in a back alleyway, or dogs interacting in the local park).

The goal of this type of project is for students to identify a behavior that can be studied, develop a hypothesis that explains the behavior in terms of a cognitive process, and design an experiment that will provide quantifiable data to test the hypothesis. In preparation for the activity, we provide specific examples of how this process unfolds in comparative cognition research. One example is the opening of milk bottles by birds in the British Isles (Fisher \& Hinde, 1949) and the subsequent tests for observational learning in this species (e.g., Sherry \& Galef, 1984, 1990). The project could be expanded to include video clips of animals in different habitats and environments, asking students to go through the same process of identifying a behavior, developing an hypothesis, and designing an experiment to test the hypothesis.

Finally, we recently adapted a group assignment for online delivery that was previously used as a culminating project in our on-campus course. The "Design your own animal" assignment is completed in the final week of the course and instructs students to think about a species that will be alive (and thriving!) in the future given the rapidly changing environment in which we live. We do not provide a time frame, but we do ask students to think "far in the future." They must consider what cognitive processes will be necessary for future survival and how these will be manifested in a particular species. In creating this future animal, each group must identify traits that have evolved from a contemporary species and then describe how these will aid with future survival and reproduction. Given our final unit topic on social 
learning, the one caveat is that the species must be a social species (i.e., living and interacting in conspecific groups). Groups prepare a 5- to 10-min presentation on their animal that is loaded online for the rest of the class to view. As an added incentive to incorporate creativity, we conclude the course with an anonymous class vote for the best project.

\section{Assessments}

Assessments in the two versions of our introductory course in comparative cognition are similar, with minor adjustments to account for online delivery. Students in both courses complete weekly quizzes that are open book and are content based. The majority of the questions test foundational knowledge, such as facts, terms, or concepts. We acknowledge that students may work on the quizzes together and use their textbook, but we impose a reasonably tight time line on quiz access (15-30 min, depending on the specific quiz) such that it would be difficult to complete the assignment without at least a basic knowledge of the chapter content. Indeed, one of the primary goals of these weekly assessments is to encourage students to keep up with the course readings throughout the term. Additionally, regular, repeated testing has retention benefits that exceed other types of studying (e.g., Roediger \& Karpicke, 2006). We build flexibility into the quiz schedule, giving students the option to miss at least two without penalty and to choose when to start the quiz within a 3-day window. (Because online courses are often chosen by students with time constraints such as work schedules and caregiving responsibilities, we have found that consistent, yet wide, time windows for assessment completion are a particularly important aspect of Universal Design for Learning to consider.) Finally, after each quiz we post summaries of class performance (e.g., means and standard errors of the mean) on each quiz and provide explanations for topics that seem to have been the most difficult for students (a type of "just in time teaching" described by Novak et al., 1999).

The weekly online activities, just described, mirror those that are conducted in learning labs (approximately 50 students) of the in-person course. Written assignments that accompany these activities in the online course (in lieu of the in-person discussion that occurs in the on-campus course) are "low stakes," often worth $1 \%-3 \%$ of a final mark, providing an ideal opportunity for students to develop their academic skills. To facilitate this, and assuming sufficient resources are available, we provide prompt and extensive feedback on both the content of their responses and the manner in which the information was communicated. Students who adjust their future work based on this feedback often improve their marks dramatically over the term, particularly as online technology allows more reflection than may occur in face-to-face classrooms (Song et al., 2004). These assignments, and the weekly quizzes, are thus considered to be formative assessments, allowing in-process evaluation and targeted focus on areas that need work.

The primary assignment in both versions of our course has both formative and summative assessment, the latter associated with one of the learning outcomes for the entire course. This written assignment is a science communication paper, recognizing that this skill is particularly valued in both academics and the workplace. The assignment is built up over an 8-week period, starting with an activity that requires students to identify factors that characterize effective science writing. To do so, we provide students with pairs of articles from the popular press that each profile the same scientific study. Students compare the two by answering a series of questions, such as, Which article provides the best description of the study? How accurate are the two titles? and Were alternative views of the findings presented? Students must also identify who wrote the articles (e.g., the media officer at the researcher's institution, a journalist, the primary researcher) and comment on the assumptions, biases, or background knowledge that may have influenced the writing. Students then use the knowledge they have gained in critiquing other pieces of writing to prepare their own science communication article about a recently published study in comparative cognition. Students often require guidance in selecting an appropriate target article, which we provide through course announcements and individual communication. A primary challenge in asynchronous online courses is maintaining consistent and timely communication (Song et al., 2004), so we ensure that both email and discussion boards are monitored consistently during this period.

The next step of the project provides formative assessment, as students develop a writing plan, including a working title, plus three to four sentences outlining the main points of the background, methods, results, conclusions, and critiques. We give extensive feedback on the writing plan, sometimes advising students to select a different paper (we do not penalize them for an inappropriate article selection at the writing plan stage). Students then use this feedback to write a full article that would be appropriate for a publication in 
an outlet such as Scientific American. One of the biggest challenges (and one that separates the B from A students in this summative assessment) is the ability to put their findings in the broader context of comparative cognition research, although we are happy to report that many of these assignments are exceptional.

In previous years, our online course had an in-person final exam that served as a summative assessment at the end of the course. The exam contained multiple-choice, short-answer, and long-answer questions, a format that had been scaffolded by the weekly formative assessments associated with the quizzes and short written assignments. Due to constraints posed by the pandemic, this exam was not held in the spring of 2020, and instead we developed a "take-home" open-book exam that was optional. The exam required a written essay in response to a question that spanned the overall themes of the course and connected with our learning outcomes. In future years, if in-person exams remain unfeasible because of financial factors or safety considerations, we will continue to use this type of assessment. However, we will develop a new activity and assignment to prepare students for the format, and we will require completion of the exam. (Please also see the Academic Integrity section that follows for considerations regarding academic integrity in online exams.) Consistent with large-scale surveys and research studies (e.g., Cavanaugh \& Jacquemin, 2015; Nguyen, 2015), we observed no difference in the course averages this year and in past years for in our in-person and online courses, although there is often greater variability in the marks of the latter group.

\section{Considerations}

In the supplemental material, we provide resources for online teaching at a broader level, regardless of course topic (General Resources for Online Teaching). There, readers will find an annotated list of considerations and links to relevant information for each. Next, we highlight two of these considerations: accessibility and academic integrity.

\section{Accessibility}

Regardless of whether instructors teach an in-person or online course, we strongly encourage those teachers to become aware of their institution's accessibility guidelines, which are likely based on government standards. It is best to meet guidelines or recommendations during the initial development of material so that the material can easily be converted into alternate formats (e.g., braille, closed captioning) or read aloud by screen readers when needed. This way, modified material will not have to be created at the "last minute" and students can be supported at the very start of the course.

Some software, such as newer versions of Microsoft Office products, have built-in templates as well as an accessibility checker that help to ensure that the most common accessibility recommendations are met. For example, in our courses we provide lecture outlines created with Microsoft Word to complement lectures and scaffold note-taking skill development. We have found that the ability to connect descriptive text (or Alt Text) to pictures or graphs is a useful way to ensure that assistive technology can convey the information demonstrated by the figure (Figure 3). We have also paid heed to the accessibility checker's warning of "hard to read text contrast"; for Figure 1 in this article, for example, the background color in the Quiz textbox was changed to a darker hue in response to the warning. Finally, if a lecture is to be saved as a movie that is embedded into a learning management system or course website, instructors may want to consider what software is available at their institution to provide subtitles, closed captions, or full transcripts.

\section{Academic Integrity}

Academic integrity is commonly conceptualized as commitment to the fundamental values of honesty, trust, fairness, respect, responsibility, and courage (Fishman, 2014). Departures from academic integrity ("cheating") are a particular concern in online courses, given the opportunities that the internet provides to enable academic dishonesty (Underwood \& Szabo, 2003). There are many ways to cheat in an online environment, including downloading papers from the internet and claiming them as one's own work, using materials without permission during an online exam, communicating with other students to obtain answers, or having another person complete an online exam or assignment rather than the student who is submitting the work (Jung \& Yeom, 2009; Rogers, 2006).

The belief that cheating occurs more often in online courses is widespread, with approximately $42 \%$ to $74 \%$ of students believing it to be easier to cheat in an online class (e.g., Kennedy et al., 2000; King \& Guyette, 2009; Rogers, 2006; Stuber-McEwen, Wiseley, \& Hoggatt, 2009; Watson \& Sottile, 2010). Despite the many studies of academic dishonesty in in-person classes, few studies have attempted to compare cheating rates between

COMPARATIVE COGNITION \& BEHAVIOR REVIEWS 


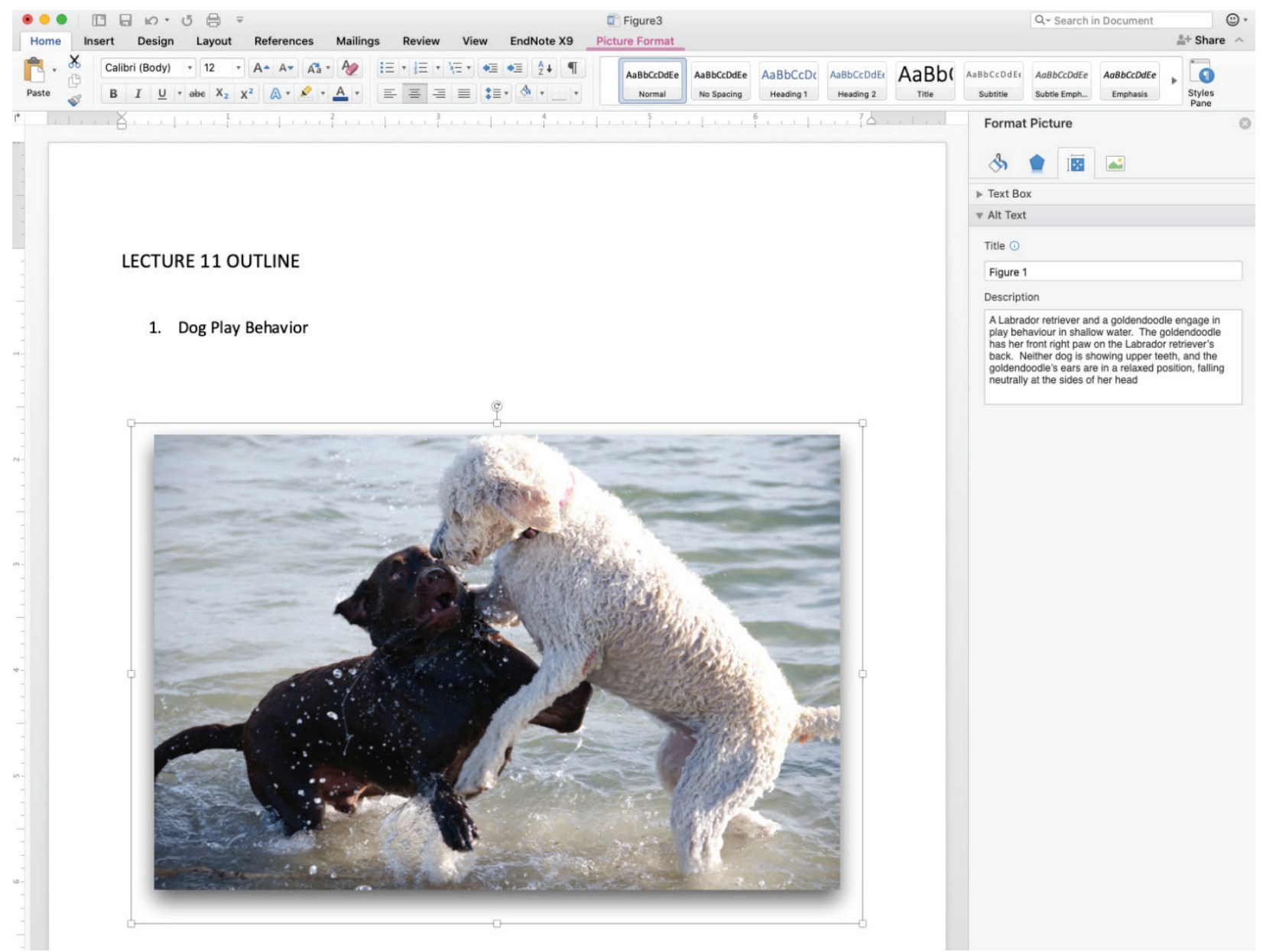

Figure 3. A screenshot depicting the Alt Text option in Microsoft Word for Mac (Version 16.16). The alternative text for this example, entered in the Description field on the right, reads, "A Labrador retriever and a goldendoodle engage in play behaviour in shallow water. The goldendoodle has her front right paw on the Labrador retriever's back. Neither dog is showing upper teeth, and the goldendoodle's ears are in a relaxed position, falling neutrally at the sides of her head." (Photo of dog play behavior used with permission from Rodney Birch.)

in-person and online classes. Some existing studies have looked at cheating across all types of online assessments in a course, whereas others have specifically focused on exams. Because of this, the results across studies appear to be inconsistent, with some studies demonstrating that cheating occurs more often in online classes than in in-person classes (Khan \& Balasubramanian, 2012; King \& Case, 2014; Lanier, 2006; Watson \& Sottile, 2010), others demonstrating equal cheating rates (Grijalva, Nowell, \& Kerkvliet, 2006; Ladyshewsky, 2015), and some demonstrating that cheating occurs more often in-person (Stuber-McEwen, Wiseley, \& Hoggatt, 2009).

Additional reasons for this discrepancy across studies are proposed in Holden, Norris, and Kuhlmeier (under review). That paper also provides a review of modern methods used to promote academic integrity, as well as prevent and detect cheating, within assessments such as online exams. (Creative Commons Licensed figures depicting methods for prevention and detection of academic dishonesty can be found via Open Science Framework: https://osf.io/46eh7/. A preprint of the Holden et al. paper can be found at https://psyarxiv.com $/ \mathrm{rjk} 7 \mathrm{~g} /$.$) Cheating prevention,$ for example, can be supported through the structure of assessments (e.g., format, content, windows of availability) and university policies (e.g., clear definitions of academic dishonesty and associated penalties). Cheating detection during online exams is much more difficult, even with modern technologies allowing for varying degrees of proctoring that range from video summation (students are recorded via webcam and potential cheating events are flagged via artificial intelligence) to web video recording (recordings of students are viewed in their entirety by instructors) to 
live online proctoring (a proctor watches a real-time video feed of students). Like Holden and colleagues, we note that these methods should be considered in concert with broader consideration of the reasons that students may engage in academic dishonesty in the first place.

\section{A Call for Community}

In this article, our goal was to describe our approach to teaching animal learning and cognition at the undergraduate level in a fully online format. The supplemental material contains annotated links for further information regarding adapting courses to the online environment, including topics such as accessibility, lecture recording, developing learning outcomes and activities, "netiquette," and academic integrity. Additionally, there is a supplemental "working document" containing annotated links for videos, podcasts, demonstrations, and so on that showcase research in animal behavior, learning, and cognition.

We consider this latter material a "working document," as we hope to add ideas, topics, and material generated from other instructors - like you! — over time. To this end, the supplemental material also contains a link to a shared document to which instructors can contribute.

In a previous paper, we provided a brief overview of training at postsecondary institutions, which suggested that comparative cognition is well represented in many undergraduate programs at English-speaking institutions in the United Kingdom and North America (Lamontagne et al., in press). Although, like others, we encourage the development of more courses - or simply better inclusion of the topic-for 1st- and 2nd-year students (Abramson, 2015; Domjam \& Purdy, 1995). We ask our community of colleagues to create and add to shared repositories of teaching resources as a means to enhance our teaching of comparative cognition and, in turn, train future researchers, foster critical thinking, exemplify the value of hypothesis testing using the scientific method, and introduce students to practical applications of the field. We hope that this article - though written with a sense of urgency given the changes in higher education during the pandemic - can start this process.

\section{Supplementary Information}

The documents can be found via the Open Science Framework at https://osf.io/mbspr/?view_only $=4120 \mathrm{cb} 78 \mathrm{c} 39 \mathrm{e} 4259 \mathrm{a} 83 \mathrm{e} 501 \mathrm{~b} 08 \mathrm{fa} 9 \mathrm{e} 83$.

\section{References}

Abramson, C. I. (2015). A crisis in comparative psychology: Where have all the undergraduates gone? Additional comments. Comprehensive Psychology, 4, 7. doi:10.2466/10.IT.4.7

Allen, I. E., \& Seaman, J. (2016). Online report card: Tracking online education in the United States. Babson Park, MA: Babson Survey Research Group and Quahog Research Group. https://eric. ed.gov/?id=ED572777

Allen, I. E., \& Seaman, J. (2017). Digital learning compass: Distance education enrollment report 2017. Babson Park, MA: Babson Survey Research Group, e-Literate, and WCET. https://onlinelearningsurvey.com/ reports/digtiallearningcompassenrollment2017.pdf

Bajak, A. (2014, May 12). Lectures aren't just boring, they ineffective, too, study finds. Science. https://www.sciencemag.org/news/2014/05/lecturesarent-just-boring-theyre-ineffective-too-study-finds

Cavanaugh, J. K., \& Jacquemin, S. J. (2015). A large sample comparison of grade based student learning outcomes in online vs. face-to-face courses. Online Learning Journal, 19, 25-32. doi:10.24059/olj.v19i2.454

Domjan, M., \& Purdy, J. E. (1995). Animal research in psychology: More than meets the eye of the general psychology student. American Psychologist, 50(7), 496-503. doi:10.1037/0003-066X.50.7.496

Educause Learning Initiative. (2014). Key issues in teaching and learning 2017. Retrieved from https:// www.educause.edu/eli/initiatives /key-issues-in-teaching-and-learning

Fenton, W. (2018, January 12). The best (LMS) learning management systems. PC Magazine. https://www.pcmag.com/picks/the-best-lms-learning -management-systems

Fink, L. D. (2013). Creating significant learning experiences, revised and updated: An integrated approach to designing college courses. San Francisco, CA: Jossey-Bass.

Fisher, J., \& Hinde, R. (1949). The opening of milk bottles by birds. British Birds, 42, 437-457. 
Fishman, T. (Ed.). (2014). The fundamental values of academic integrity, second edition. Licensed by the International Center for Academic Integrity under Creative Commons Attribution-NonCommercialShareAlike 4.0 International. https://www .academicintegrity.org/wp-content/uploads/2017/12 /Fundamental-Values-2014.pdf

Flemming, T. M., \& Kennedy, E. H. (2011).

Chimpanzee (Pan troglodytes) relational matching: Playing by their own (analogical) rules. Journal of Comparative Psychology, 125, 207-215. doi:10.1037/a0022098

Fostaty Young, S. \& Wilson, R. J. (2000). Assessment and learning: The ICE approach. Winnipeg, MA: Portage and Main Press.

Freeman, S., Eddy, S. L., McDonough, M., Smith, M. K., Okoroafor, N., Jordt, H., \& Wenderoth, P. (2014). Active learning increases student performance in science, engineering, and mathematics. Proceedings of the National Academy of Sciences of the United States of America, 111(23), 8410-8415. doi:10.1073/pnas.1319030111

Grijalva, T., Nowell, C., \& Kerkvliet, J. (2006). Academic honesty and online courses. College Student Journal, 40(1), 180-185.

Holden, O. L., Norris, M. E., \& Kuhlmeier, V. A. (under review). Academic integrity in online testing: A research review. The Internet and Higher Education.

Hounsell, D., \& Anderson, C. (2008). Ways of thinking and practicing in biology and history: Disciplinary aspects of teaching and learning environments. In C. Kreber (Ed.), The university and its disciplines: Teaching and learning within and beyond disciplinary boundaries (Section II). London: Routledge.

Jaschik, S., \& Lederman, D. (Eds.) (2018). 2018 Survey of Faculty Attitudes on Technology: A study by Inside Higher Ed and Gallup. https://www. insidehighered.com/system/files/media/IHE_2018 _Survey_Faculty_Technology.pdf
Jung, I. Y., \& Yeom, H. Y. (2009). Enhanced security for online exams using group cryptography. IEEE Transactions on Education, 52(3), 340-349. doi:10.1109/TE.2008.928909

Kennedy, K., Nowak, S., Raghuraman, R., Thomas, J., \& Davis, S. F. (2000). Academic dishonesty and distance learning: student and faculty views. College Student Journal, 34, 309-314. doi:10.1109 /TE.2008.928909

Khan, Z., \& Balasubramanian, S. (2012). Students go click, flick and cheat... e-cheating, technologies, and more. Journal of Academic and Business Ethics, 6, 1-26.

King, D. L., \& Case, C. J. (2014). E-cheating: Incidence and trends among college students. Issues in Information Systems 15(1), 20-27.

King, D. L., \& Guyette, R. (2009). Online exams and cheating: An empirical analysis of business students' views. Journal of Educators Online, 6. doi:10.9743/JEO.2009.1.5

Kolomitro, K., \& Gee, K. (2015). Developing effective learning outcomes: A practical guide. Centre for Teaching and Learning, Queen's University, Kingston, Ontario, Canada. https://www.queensu .ca/ctl/sites/webpublish.queensu.ca.ctlwww/files /files/Publications/Developing\%20Effective $\% 20$ Learning $\% 20$ Outcomes $\% 20$ Guide $\% 20$ May $\% 202015 \% 20$ creative $\% 20$ commons.pdf

Ladyshewsky, R. K. (2015). Post-graduate student performance in 'supervised in-class' vs. 'unsupervised online' multiple choice tests: implications for cheating and test security. Assessment \& Evaluation in Higher Education, 40(7), 883-897. doi:10.1080/02602938.2014.956683

Lambert, C. (2012, March-April). Twilight of the lecture. Harvard Magazine. https://www.harvardmagazine.com /2012/03/twilight-of-the-lecture

Lamontagne, S. J., Kuhlmeier, V. A., \& Olmstead, M. C. (in press). Comparative cognition and cognitive ecology in the classroom. Canadian Journal of Experimental Psychology. 
Lanier, M. (2006). Academic integrity and distance learning. Journal of Criminal Justice Education, 17, 244-261. doi:10.1080/10511250600866166

Le, A., Joordens, S., Chrysostomou, S., \& Grinnell, R. (2010). Online lecture accessibility and its influence on performance in skills-based courses. Computers and Education, 55(1), 313-319. doi:10.1016/j.compedu.2010.01.017

Leadbeater, W., Shuttleworth, T., Couperthwaite, J., \& Nightingale, K. P. (2013). Evaluating the sue and impact of lecture recording in undergraduates: Evidence for distinct approaches by different groups of students. Computers \& Education, 61, 185-192. doi:10.1016/j.compedu.2012.09.011

Nguyen, T. (2015). The effectiveness of online learning: beyond no significant difference and future horizons. Journal of Online Learning and Teaching, 11(2), 309-319.

Novak, G., Patterson, E. T., Gavrin, A. D., \& Christian, W. (1999). Just-in-time teaching: Blending active learning with web technology. Upper Saddle River, NJ: Prentice-Hall. doi:10.1119/1.19159

Rhode, J., Richter, S., Gowen, P., Miller, T., \& Wills, C. (2017). Understanding faculty use of the learning management system. Online Learning, 21(3), 68-86. doi:10.24059/olj.v\%vi\%i.1217

Roediger, H. L., III, \& Karpicke, J. D. (2006). Testenhanced learning: Taking memory tests improves long-term retention. Psychological Science, 17(3), 249-255. doi:10.1111/j.1467-9280.2006.01693.x

Rogers, C. (2006). Faculty perceptions about e-cheating during online testing. Journal of Computing Sciences in Colleges, 22, 206-212.

Russell, G. (2014, October 26). The Problem Solvers: Inside the Animal Mind. BBC.

Sherry, D. F., \& Galef, B. G. (1984). Cultural transmission without imitation: Milk bottle opening by birds. Animal Behaviour, 32, 937-938. doi:10.1016/S0003-3472(84)80185-2
Sherry, D. F., \& Galef, B. G. (1990). Social-learning without imitation: more about milk bottle opening by birds. Animal Behaviour, 40, 987-989. doi:10.1016/S0003-3472(05)81004-8

Small, A. (2014, May 27). In defense of the lecture. The Chronicle of Higher Education. Retrieved from https://www.chronicle.com/article/In-Defense -of-the-Lecture/146797

Song, L., Singleton, E. S., Hill, J. R., \& Koh, M. H. (2004). Improving online learning: Student perceptions of useful and challenging characteristics. The Internet and Higher Education, 7(1), 59-70. doi:10.1016/j.iheduc.2003.11.003

Stuber-McEwen, D., Wiseley, P., \& Hoggatt, S. (2009). Point, click, and cheat: Frequency and type of academic dishonesty in the virtual classroom. Online Journal of Distance Learning Administration, 12(3).

Underwood, J., \& Szabo, A. (2003). Academic offences and e-learning: individual propensities in cheating. British Journal of Educational Technology, 34(4), 467-477. doi:10.1111/1467-8535.00343

Watson, G., \& Sottile, J. (2010). Cheating in the digital age: Do students cheat more in online courses? Online Journal of Distance Learning Administration, 13(1). http://www.westga.edu/ distance/ojdla/ spring131/watson131.html

World Health Organization Director-General. (2020, March 16). WHO Director-General's opening remarks at the media briefing on COVID-19 March 2020. https://www.who.int/director-general /speeches/detail/who-director-general-s-opening -remarks-at-the-media-briefing-on-covid-19---16 -march-2020

World Health Organization. (2020, June 23). Coronavirus disease (COVID-19) pandemic. https://www.who.int/emergencies/diseases /novel-coronavirus-2019

Worthen, M. (2015, October 17). Lecture me. Really. The New York Times. https://www.nytimes.com /2015/10/18/opinion/sunday/lecture-me-really.html

COMPARATIVE COGNITION \& BEHAVIOR REVIEWS 